\title{
The effect of placenta previa on fetal weight and feto-maternal blood flow: a prospective cohort study
}

\author{
Mohammed K. Ali ${ }^{1}$, Islam S. Mahfouz ${ }^{2}$, Ahmed M. Abbas*1, Ezzat H. Sayed ${ }^{1}$
}

\begin{abstract}
${ }^{1}$ Department of Obstetrics and Gynecology, Faculty of Medicine, Assiut University, Assiut, Egypt
${ }^{2}$ Department of Obstetrics and Gynecology, Assiut General Hospital, Assiut, Egypt
\end{abstract}

Received: 21 August 2018

Accepted: 27 September 2018

\section{*Correspondence:}

Dr. Ahmed M. Abbas,

E-mail: bmr90@hotmail.com

Copyright: () the author(s), publisher and licensee Medip Academy. This is an open-access article distributed under the terms of the Creative Commons Attribution Non-Commercial License, which permits unrestricted non-commercial use, distribution, and reproduction in any medium, provided the original work is properly cited.

\begin{abstract}
Background: The current study aims to evaluate the effect of placenta previa on the fetal weight and to explore its effect on the uterine and umbilical arteries blood flow.

Methods: The current study was a prospective cohort study conducted at Assiut Women's Health Hospital, Egypt from 1st of October 2016 to 30th of September 2017 including placenta previa and non-placenta previa women. They were followed up by two-dimensional ultrasound and Doppler blood flow in the uterine and umbilical arteries. The main study outcome was the number of low birth weight (LBW) babies delivered at or beyond 37 weeks and blood flow changes in uterine and umbilical arteries.

Results: Two hundred twelve women were divided into two groups; group I included 106 placenta previa women (PP group) and 106 non-placenta previa women (NPP group). The number of LBW babies were comparable in both groups without statistically significant difference $(\mathrm{P}$ value= 0.555$)$. Neither; uterine artery nor umbilical artery blood flow had any significant differences between the groups. Preterm delivery was significantly higher in the PP group ( $\mathrm{p}$ value $=0.000$ ).

Conclusions: Although there is no agreement, in the literature, on the association between placenta previa and LBW, authors suggest that placenta previa is not a reason for LBW babies. In addition, placenta previa shows no effect on uterine artery or umbilical artery blood flow.
\end{abstract}

Keywords: Doppler blood flow, Low birth weight, Placenta previa, Preterm birth

\section{INTRODUCTION}

Placenta previa is a placenta that implants at lower uterine segment, it occurs in about $0.3-0.5 \%$ of pregnancies at term. ${ }^{1}$ It is a significant risk factor for development of maternal morbidity, as well as maternal mortality secondary to maternal hemorrhage. ${ }^{2}$ This abnormal placenta has a negative consequence on fetal wellbeing due to prematurity and perinatal mortality, in addition to its undesirable effect on fetal growth. ${ }^{3}$ Several factors may be behind its effect on fetal growth. Firstly, the blood supply to the lower uterine segment is less than at the upper segment apparently resulting in less fetoplacental blood perfusion. ${ }^{4}$ Secondly, recurrent bleeding attacks from placental previa may affect fetal oxygenation and fetal growth. ${ }^{5}$ Some small studies in literature confirmed the relation between placenta previa and decreased fetal growth, while most of themothers denied this relation and concluded that the association between LBW and placenta previa is mainly due to preterm delivery and to a lesser extent with fetal growth restriction. ${ }^{3,6-11}$ 
However; the major drawback of all these mentioned studies is lacking reporting the effect of placenta previa of feto-maternal blood flow which can give the obstetricians the appropriate explanation of this association. Placenta previa/accreta originates from abnormal trophoblast invasion and the previous studies suggested that the uterine artery blood flow may be affected in such cases pointing to impaired placentation. ${ }^{12}$ The uterine artery Doppler velocimetry was studied before and was used to differentiate between accreta and non accreta one. ${ }^{13}$

So, in the light of above evidences; authors aimed, in the current study, not only to investigate the effect of placenta previa on fetal weight but also to walk around the effect of placenta previa on the uterine and umbilical arteries blood flow in trial to explore this conflicting issue. To our knowledge, no previous trial had studied this interesting subject before.

\section{METHODS}

The current study was a clinically registered prospective cohort study (NCT03321435) compassing the effect of placenta previa on fetal weight and feto-maternal blood flow. The ethical review board of Assiut Faculty of Medicine approved the study. The study participants were recruited from the Obstetric Outpatient Clinic, Woman's Health Hospital, Assiut University, Egypt from $1^{\text {st }}$ of October 2016 to $30^{\text {th }}$ of September 2017. Women who met the selection criteria of the study were invited to participate and only those who signed the informed consent were recruited.

\section{Inclusion criteria}

- Authors included in present study women aged 20-35 years, with BMI $18-22 \mathrm{~kg} / \mathrm{m}^{2}$ who were pregnant in a singleton baby with estimated gestational age ranging between 28-30 weeks gestation.

- The study included two groups: group I-the case group, those had been diagnosed to have placenta previa by trans-abdominal ultrasound either asymptomatic or had minimal vaginal bleeding at time of participation. Group II-control group had the same inclusion criteria of the cases but with normal situated placenta.

- Lastly, all recruited women had normal Doppler indices in umbilical and uterine arteries at time of recruitment (the normal value of S/D ratio is from 2.5 to 3.5 ; RI is from 0.60 to 0.75 and of PI is from 0.96 to 1.270 , respectively). ${ }^{14}$

\section{Exclusion criteria}

- Authors excluded women aged $<20$ and $>35$ years, smokers $\geq 11$ cigarettes/day, had multiple gestations, previous history of intrauterine growth restricted fetus, intrauterine fetal death or major fetal anomalies, low amniotic fluid volume, pre-labor rupture of membranes, feto-maternal instability, associated with abruptio placenta, had bleeding disorders or on anticoagulant therapy.

- Finally, women had any medical disorders as hypertension, diabetes, and hepato-renal impairment or abnormal Doppler indices at the time of recruitment in the form of Doppler indices $>2$ SDs, absent diastolic flow or reversed flow were also excluded.

The participated women were entered the screening phase of the study, which included history taking (about parity and gestational age which confirmed by revising the given reliable $1^{\text {st }}$ day of last menstrual period or having 1st trimester US confirming gestational age). All risks factors for IUGR and placenta previa were revised. ${ }^{15,16}$ Active vaginal bleeding was assessed in placenta previa women by inspection of the soaked pads and amount of blood clots. Clinical examinations including BMI, blood pressure and symphysial-fundal height (SFH) were also assessed.

Then all participant women were subjected to twodimensional trans-abdominal ultrasound (2 D TA/US) using Sonoline G60 S ultrasound imaging system, Siemens, Germany; with a convex probe $3.5 \mathrm{MHz}$ to assess the gestational age, liquor volume and fetal heart motion. The site and degree of placenta previa were also determined. The placenta previa was considered a major praevia if the placenta lies over the internal cervical os and if the lower edge of the placenta is in the lower uterine segment but not covering the cervical os, it was minor or partial praevia. ${ }^{15}$

After that; the umbilical artery Doppler blood flow was measured at free loop of umbilical cord (using the same mentioned machine). The uterine artery Doppler blood flow was measured with patients in the recumbent position with slight left lateral tilt. The blood flow velocity waveform was studied in the main trunk of both right and left uterine arteries, $2-3 \mathrm{~cm}$ medial to the anterior superior iliac spine. The average value of systolic/ diastolic ration (S/D), resistance index (RI) and pulsatility index (PI) was calculated when three similar consecutive waves were obtained. ${ }^{17}$

The primary outcome of this study was the percentage of LBW babies delivered at or beyond 37 weeks. LBW was defined as birth weight $<2,500 \mathrm{~g}$ at $\geq 37$ weeks. $^{18}$ Secondary outcomes included the effect of placenta previa on umbilical and uterine artery blood flow. In addition, authors also assessed the impact of placenta previa site and symptomatic placenta previa on the fetal growth.

The placenta previa women were encouraged to come to follow up every two weeks. At each visit; authors assessed them clinically by asking them about number and pattern of vaginal bleeding and adequacy of fetal movement. SFH was recorded at each visit. 2D TA/US 
and Doppler blood flow were used to assess estimated fetal weight and blood flow in both umbilical and uterine arteries. Unscheduled ultrasound examinations \pm cardiotocography was done for any fetal-maternal indications as attacks of ante-partum haemorrhage, decreased fetal movement, suspected PROM or preterm labour. As regard the non-placenta previa patients (control group), they were followed up every 4 weeks by 2 D TA/US and Doppler blood flow.

Sample size calculation was calculated based on the primary outcome (percentage of LBW babies delivered at or beyond 37 weeks). The previous retrospective cohort study reported that placenta previa is associated with LBW in about $30 \% .^{7}$ Using two-sided chi-square $\left(\chi^{2}\right)$ test with $\alpha$ of 0.05 , a total sample size of at least 212 patient (106 in each arm) will have $80 \%$ power detect a $15 \%$ difference assuming a rate of loss to follow-up of $10 \%$ (Epi-info TM, CDC, USA).

\section{Statistical analysis}

The data was collected and entered onto Microsoft access database to be analyzed using the Statistical Package for Social Science (SPSS Inc., Chicago, version 21). Comparisons between two groups were done using Student's t-test to compare the mean values between groups in scale variables. However, $\mathrm{Chi}^{2}$ test was used to compare the dichotomous and ordinal variables in the groups. For analysis $\mathrm{P}<0.05$ will be considered significant. For non-parametric continuous or categorical data, suitable tests as Fisher exact and Man-Whitney tests were used.

\section{RESULTS}

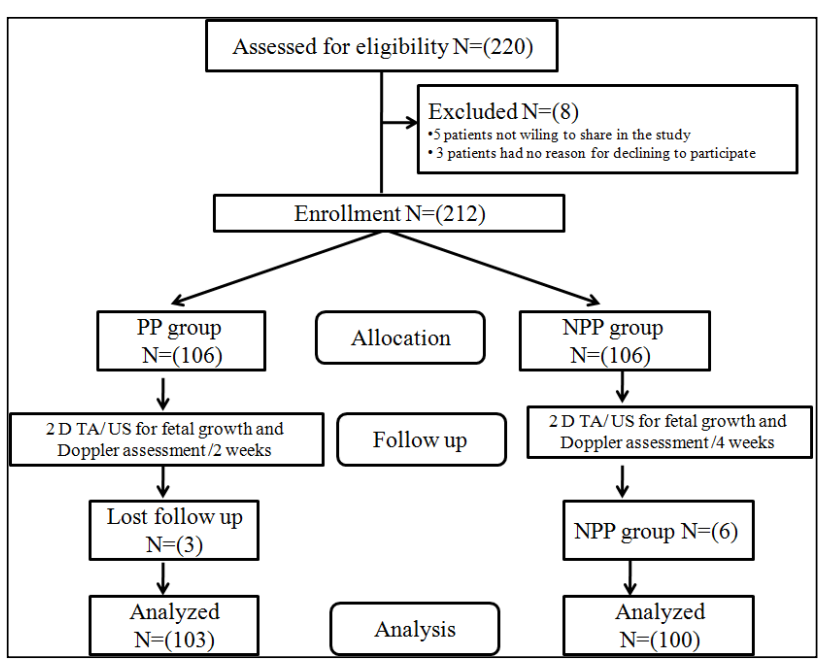

Figure 1: The study flowchart.

Two hundred twenty women were counselled for participation, however; 8 women refused to participate. Two hundred twelve women consented to participate and divided into two groups; group I included 106 PP women and 106 NPP women.
About $95 \%$ of the study participants had completed their scheduled follow-up visits until delivery (Figure 1, the study flow chart).

Both groups were homogenous in baseline sociodemographic data without statistically significant differences (Table 1). However; the PP group had a higher number of previous cesarean section (CS) than NPP group with statistically significant difference (71, $66.9 \%$ versus $40,37.7 \%$; $\mathrm{p}=0.000$ ) (Table 1 ).

Table 1: Demographic characteristics of PP women and NPP women.

\begin{tabular}{|c|c|c|c|}
\hline $\begin{array}{l}\text { Clinical } \\
\text { characteristics }\end{array}$ & $\begin{array}{l}\text { PP } \\
\text { group } \\
\mathrm{N}=106\end{array}$ & $\begin{array}{l}\text { NPP } \\
\text { group } \\
\mathrm{N}=106\end{array}$ & $P$ value \\
\hline \multicolumn{4}{|l|}{ Age (years), n (\%) } \\
\hline$<20$ & $22(20.7)$ & $35(33)$ & \multirow{3}{*}{0.225} \\
\hline $21-30$ & $35(33)$ & $31(29.3)$ & \\
\hline$>30$ & $48(45.2)$ & $40(37.7)$ & \\
\hline \multicolumn{4}{|l|}{ Residency, n (\%) } \\
\hline Rural & $33(31.2)$ & $36(34)$ & \multirow{3}{*}{0.408} \\
\hline Semi urban & $39(36.8)$ & $30(28.3)$ & \\
\hline Urban & $34(32)$ & $40(37.7)$ & \\
\hline \multicolumn{4}{|c|}{ Level of education, $\mathrm{n}(\%)$} \\
\hline Illiteracy & $49(46.2)$ & $42(39.6)$ & \multirow{6}{*}{0.651} \\
\hline Read and write & $32(30.2)$ & $31(29.3)$ & \\
\hline Primary & $12(11.3)$ & $16(15)$ & \\
\hline Preparative & $1(0.94)$ & $2(1.9)$ & \\
\hline Secondary & $8(7.6)$ & $13(12.2)$ & \\
\hline Academic & $4(3.8)$ & $2(1.9)$ & \\
\hline \multicolumn{3}{|c|}{ Woman's work, n (\%) } & \multirow{3}{*}{0.106} \\
\hline Housewife & $62(58.5)$ & $70(66)$ & \\
\hline Employee & $44(41.5)$ & $36(34)$ & \\
\hline $\begin{array}{l}\text { Number of previous } \\
\text { abortions, } \mathrm{n}(\%)\end{array}$ & $11(10.3)$ & $19(17.9)$ & 0.675 \\
\hline Previous CS, n (\%) & $71(66.9)$ & $40(37.7)$ & $0.000 *$ \\
\hline Parity, mean \pm SD & $3.8 \pm 1.9$ & $3.7 \pm 1.9$ & 0.916 \\
\hline $\begin{array}{l}\text { Number of living } \\
\text { children, mean } \pm \text { SD }\end{array}$ & $2.4 \pm 0.99$ & $2.3 \pm 0.98$ & 0.369 \\
\hline $\begin{array}{l}\text { Duration from last } \\
\text { pregnancy (years), } \\
\text { mean } \pm \text { SD }\end{array}$ & $3.8 \pm 1.8$ & $3.7 \pm 1.7$ & 0.573 \\
\hline $\begin{array}{l}\text { Gestational age } \\
\text { (weeks), mean } \pm \text { SD }\end{array}$ & $29.1 \pm 0.9$ & $28.9 \pm 0.9$ & 0.262 \\
\hline $\begin{array}{l}\mathrm{BMI}\left(\text { weight } / \mathrm{kg}^{2}\right) \\
\text { mean } \pm \mathrm{SD}\end{array}$ & $22.18 \pm 4.4$ & $23.32 \pm 5.1$ & 0.084 \\
\hline
\end{tabular}

Twenty PP women (18.8\%) had previous history of placenta previa in previous pregnancies. Half of PP women (53 women; 50\%) had not any vaginal bleeding at 28-30 weeks.

At 36 weeks; authors found that only $30 \mathrm{PP}$ women $(28.3 \%)$ still had not any attacks of vaginal bleeding (Table 2). 
Table 2: Data related to placenta previa women only.

\begin{tabular}{|c|c|}
\hline Characteristics & n $(\%)$ \\
\hline Previous history of placenta previa & $20(18.8)$ \\
\hline \multicolumn{2}{|c|}{ Number of bleeding attack at $28-30$ weeks } \\
\hline No bleeding & $53(50.0)$ \\
\hline $1-3$ attacks & $44(41.5)$ \\
\hline$>3$ attacks & $9(8.5)$ \\
\hline \multicolumn{2}{|l|}{ Number of bleeding attack at 36 weeks } \\
\hline No bleeding & $30(28.3)$ \\
\hline $1-3$ attacks & $56(52.8)$ \\
\hline$>3$ attacks & $20(18.8)$ \\
\hline
\end{tabular}

Authors found that 76 PP women (71.6\%) had anteriorly situated placenta; out of them 45 women (59\%) with placenta previa major degree and 31 women $(40.7 \%)$ placenta previa minor degree. While $30 \mathrm{PP}$ women $(28.4 \%)$ had posteriorly situated placenta; out of them 24 women $(22.6 \%)$ with placenta previa major degree and 6 women $(5.6 \%)$ placenta previa minor degree. There was a significant statistically difference between the group as regard the placental site $(\mathrm{p}=0.000)$ (Table 3$)$. The women with placenta previa posterior, had a higher rate of bleeding than placenta previa anterior at 28-30 weeks gestations $(56.6 \%$ versus $34.2 \%)$ and at 36 weeks gestations ( $80 \%$ versus $68.4 \%$ ) but without statistically significant difference $(\mathrm{p}=0.234, \mathrm{p}=0.548$; respectively) (Table 3).

Table 3: Site of the placenta and antepartum hemorrhage at 28-30 weeks and at 36 weeks in PP women.

\begin{tabular}{|c|c|c|c|}
\hline \multicolumn{4}{|c|}{ Site of the placenta, $n(\%)$} \\
\hline & $\begin{array}{l}\text { Anterior } \\
(n=76)\end{array}$ & $\begin{array}{l}\text { Posterior } \\
(\mathbf{n}=30)\end{array}$ & $P$ value \\
\hline Major & $45(59.3)$ & $24(22.6)$ & \multirow{2}{*}{$0.000^{*}$} \\
\hline Minor & $31(40.7)$ & $6(5.6)$ & \\
\hline \multicolumn{4}{|c|}{ Antepartum hemorrhage at $28-30$ weeks, n (\%) } \\
\hline & $\begin{array}{l}\text { Anterior } \\
(n=26 / 76)\end{array}$ & $\begin{array}{l}\text { Posterior } \\
(n=17 / 30)\end{array}$ & $P$ value \\
\hline Major & $19(76)$ & $14(82.3)$ & \multirow{2}{*}{0.234} \\
\hline Minor & $17(24)$ & $3(17.7)$ & \\
\hline \multicolumn{4}{|c|}{ Antepartum hemorrhage at 36 weeks, n (\%) } \\
\hline & $\begin{array}{l}\text { Anterior } \\
(n=52 / 76)\end{array}$ & $\begin{array}{l}\text { Posterior } \\
(n=24 / 30)\end{array}$ & $P$ value \\
\hline Major & $33(63.4)$ & $20(83.3)$ & \multirow{2}{*}{0.548} \\
\hline Minor & $19(36.5)$ & $4(16.3)$ & \\
\hline
\end{tabular}

*statistical significance if $\mathrm{p}$-value less than 0.05 .

Table 4: Doppler blood flow indices in uterine and umbilical arteries.

\begin{tabular}{|lllllll|}
\hline Doppler indices mean \pm SD & PP group N=106 & \multicolumn{2}{l}{ NPP group N=106 } & \multicolumn{2}{l|}{ Inter-group comparisons p-value } \\
\hline End point & $\mathbf{2 8 - 3 0}$ weeks & $\mathbf{3 6}$ weeks & $\mathbf{2 8 - 3 0}$ weeks & $\mathbf{3 6}$ weeks & $\mathbf{2 8 - 3 0}$ weeks & $\mathbf{3 6}$ weeks \\
\hline Uterine artery & & & & & & \\
\hline S/D & $2.8 \pm 0.5$ & $2.7 \pm 0.5$ & $2.7 \pm 0.5$ & $2.6 \pm 0.5$ & 0.436 & 0.313 \\
\hline RI & $0.7 \pm 0.8$ & $0.7 \pm 0.04$ & $0.6 \pm 0.05$ & $0.6 \pm 0.05$ & 0.211 & 0.378 \\
\hline PI & $1.4 \pm 0.2$ & $1.5 \pm 0.2$ & $1.5 \pm 0.2$ & $1.4 \pm 0.2$ & 0.264 & 0.411 \\
\hline Umbilical artery & & & & & & 0.623 \\
\hline S/D & $2.8 \pm 0.5$ & $2.8 \pm 0.4$ & $2.7 \pm 0.5$ & $2.7 \pm 0.7$ & 0.392 & 0.274 \\
\hline RI & $0.7 \pm 0.05$ & $0.7 \pm 0.05$ & $0.6 \pm 0.05$ & $0.6 \pm 0.05$ & 0.09 & 0.282 \\
\hline PI & $1.5 \pm 0.2$ & $1.4 \pm 0.2$ & $1.4 \pm 0.2$ & $1.4 \pm 0.2$ & 0.166 & \\
\hline
\end{tabular}

S/D systolic/ diastolic, RI resistant index, PI pulsatility index.

Table 5: Fetal and delivery data in both groups.

\begin{tabular}{|c|c|c|c|}
\hline & PP group $N=103$ & NPP group $\mathrm{N}=100$ & P value \\
\hline Fetal weight at $28-30$ weeks, mean \pm SD & $1090 \pm 55$ & $1093 \pm 55$ & 0.755 \\
\hline Fetal weight at 36 weeks, mean \pm SD & $2527 \pm 88$ & $2525 \pm 88$ & 0.874 \\
\hline Time of delivery (weeks), mean \pm SD & $36.8 \pm .5$ & $38.0 \pm 1.3$ & $0.000^{*}$ \\
\hline \multicolumn{4}{|l|}{ Route of delivery, n (\%) } \\
\hline Vaginal & $7(6.7)$ & $75(75)$ & \multirow{2}{*}{$0.000 *$} \\
\hline Cesarean section & $96(93.2)$ & $25(25)$ & \\
\hline Number of LBW babies, $\mathrm{n}(\%)^{\#}$ & $18(28.5)$ & $13(14.6)$ & 0.555 \\
\hline Number of term babies & $63(61.1)$ & $89(89)$ & $0.000^{*}$ \\
\hline Number of preterm babies & $36(34.9)$ & $7(7)$ & \multirow{3}{*}{$0.000 *$} \\
\hline Spontaneous preterm & $21(58.4)$ & $7(100)$ & \\
\hline Severe attack of bleeding & $15(41.6)$ & $0(0)$ & \\
\hline Birth weight (gm), mean \pm SD & $2560 \pm 412$ & $3674 \pm 302$ & $0.000^{*}$ \\
\hline Number of stillbirths & $4(3.8)$ & $2(2)$ & 0.341 \\
\hline
\end{tabular}

*statistical significance if $\mathrm{p}$-Value less than 0.05 , \# Low birth weight babies included babies delivered at or beyond 37 weeks. 
The uterine artery S/D, RI and PI indices and the umbilical artery S/D, RI and PI indices were comparable at the baseline and 36 weeks of gestation in both groups without statistically significant differences (Table 4).

In addition, both groups were comparable in mean fetal weight at 28-30 weeks and at 36 weeks gestation without statistically significant differences $(\mathrm{p}=0.755,0.874$; respectively) (Table 5). The PP women were delivered earlier than NPP women with statistically significant difference ( 36.8 weeks Vs 38.0 weeks; p=0.000) (Table 5). Most of PP women (96; 93.2\%) were delivered by CS, in contrast; most of NPP women $(75 ; 75 \%)$ were delivered vaginally. So, there was statistically significant difference between both groups as regard route of delivery $(\mathrm{p}=0.000)$ (Table 5).

Authors found that both groups were homogenous in number LBW babies without statistically significant difference $(\mathrm{P}=0.555)$. However; there was statistically significant difference in number of term babies, the NPP women had higher number than PP women (89 versus 63; $\mathrm{P}=0.000)$. In contrast, the PP women had higher number of preterm babies than reported by NPP women (36 versus $7 ; \mathrm{p}=0.000)$. Twenty-one preterm babies $(58.4 \%)$ in PP women, out of 36 were delivered spontaneous while 15 preterm babies $(41.6 \%)$ were delivered due to sever attack of vaginal bleeding needed immediate intervention. On the other hand, all preterm babies in NNP group (7 preterm babies) were delivered spontaneously. The mean birth weight in PP group $(2560 \pm 412 \mathrm{gm})$ was lower that reported by NPP group $(3674 \pm 302 \mathrm{gm})$ with statistically significant difference $(\mathrm{p}=0.000)$. Finally; there were 4 PP women $(3.8 \%)$ and 2 NPP women (2\%) their pregnancies had been complicated by still birth (Table 5).

\section{DISCUSSION}

Up to our knowledge, this is the first study compassing the effect of PP on fetal weight and feto-maternal blood flow. The present work demonstrated that the PP hasn't any effect on fetal weight. In addition, no significant consequence was seen on uterine or umbilical artery Doppler blood flow from the PP.

LBW (birth weight $<2500 \mathrm{~g}$ ) is a significant predictor of mortality and morbidity in the neonatal period. ${ }^{19}$ About $6 \%$ of all babies are estimated to be born with a LBW. ${ }^{20}$ The LBW may be due to poor maternal nutrition, infections during pregnancy, preterm birth, multiple pregnancies, intrauterine growth restriction (IUGR) and finally, history of prior low birth deliveries increases the chance of a low birth delivery subsequently. ${ }^{21}$ It differs from IUGR which is defined as failure of the fetus to attain its normal genetic growth and specific measures threshold along a normal centiles. ${ }^{17}$

Although the true etiology of PP is weakly understood, several factors may be behind its development such as increased maternal age. ${ }^{22}$ Authors noticed that most of PP patients were aged more 30 years (45\%). However; authors found no significant difference between PP women and NPP women as regard the age, in contrast to Yeniel et al, who reported that there was a significant difference in the age between PP women and NPP women. ${ }^{7}$ This may be due un equal sample size groups in his retrospective study (123 PP women versus 11911 NPP women).

Multiparity is considered as an important risk factor for development of PP. present results showed that no significant difference was identified between the groups. Again; this is different from Ananth et al results who considered the multiparity as a significant risk factor for development of PP, but higher number included in his study (2744 PP women) may be behind this result. ${ }^{10}$

The uterine surgery is still the major risk factor for development of PP. ${ }^{23}$ The only uterine surgery reported in present study was the CS. The previous CS was reported in about $52 \%$ in present study participants (71 PP women and 40 NPP women). This means that about $52 \%$ in present study population were delivered by CS. This had been reported in a recent study by Ana in 2016 who concluded that the CS rate in Egypt is about 51.8\%. ${ }^{24}$ The fact that the CS is the most common and most important risk factor for development of PP was proved in many reports in literature keeping us at the same track. , $^{85-28}$ The last risk factor which was identified in present study is the previous history of PP. Authors found that $20 \mathrm{PP}$ patients $(18.8 \%)$ had a previous history of placenta previa. Kollmann et al reported a less number than authors reported (10.8\%); authors think this due to much less number of previous CS that reported in his study $(52 \% \text { versus } 22.8 \%)^{8}$

Weiner et al proved that the symptomatic PP is associated with increased placental mal-perfusion, so it is associated with increased maternal and neonatal morbidity and mortality. ${ }^{5}$ Authors found that half of PP women (50\%) started to have one or more attacks of vaginal bleeding at 28-30 weeks gestation. This is in accordance with Sekiguchi et al who found also that gestational age at bleeding onset was 30 weeks. ${ }^{29}$ This can be explained as the PP bleeding usually starts at third-trimester because it thought to occur in association with the development of the lower uterine segment in the third trimester. ${ }^{29}$ So as the pregnancy progressed, authors found that only 30 PP women $(28.3 \%)$ still had not any attacks of vaginal bleeding at 36 weeks.

Authors found that most of PP women (71.6\%) had anteriorly situated placenta, while only 30 PP women $(28.4 \%)$ had posterior one. present results were completely different from Sekiguchi and Hebbar who found in their studies that most of PP women had posterior situated placenta. ${ }^{29-31}$ But authors were in agreement with Sowjanya and Hong results who found that most of PP women had anterior placenta. ${ }^{32,33} \mathrm{~A}$ 
higher number of anterior PP in present study may be a result from higher rate CS. Moreover; authors found that posterior PP had a higher rate of bleeding than anterior one. This is similar to Sekiguchi who noticed the same finding. ${ }^{31}$ This fact is not clearly understood. Ishibashi, in a very recent study, supposed that cervical varicosities were frequently observed in cases of posterior PP and these varicosities have been associated with massive hemorrhage in patients with this condition. ${ }^{34}$

Authors tried to explore the relationship between PP and Doppler blood flow in both uterine and umbilical arteries which has not been investigated previously. Authors hypothesized that the effect of PP on fetal growth might be secondary to its effect on fetal (umbilical artery) and maternal (uterine artery) blood flow. Present study showed no significant differences regarding this subject. The heterogenicity of present PP patients (symptomatic/asymptomatic PP) (anterior/posterior PP), (major/minor PP), may be the cause of this result.

The mean fetal weight at 28-30 weeks and at 36 weeks in PP women was comparable with NPP women. Authors chose 28-30 weeks as the first station to assess fetal weigh because the fetal growth restriction caused by PP usually occurred late in gestation (after 28 weeks). ${ }^{17}$ Authors preferred 36 weeks as the end point because PP women usually delivered at \pm 36 weeks, so there will be no available data to be compared with. ${ }^{15}$ Authors noticed that the time of delivery in PP women $(36.8 \pm 0.5)$ was

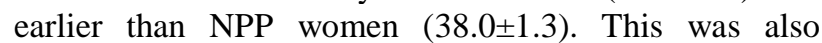
reported by Yeniel, Weiner and Kollmann who found that mean age of delivery of PP women was less than NPP women. $5,7,8$

Many studies in literature proved the positive correlation between the PP and preterm uterine contractility and also reported that women who have PP associated with vaginal bleeding will have subclinical uterine contractions before the onset of evident vaginal bleeding. ${ }^{35}$ Authors found that most of preterm babies passed spontaneous into labour. The same fact was published by Ananth and Yeniel in their studies. ${ }^{7,10}$ However; authors did not find any relation between PP and LBW babies. But authors disagree with Yeniel because he found a significant difference between PP women and NPP women as regard number of LBW babies. $^{7}$ A huge number of NPP women (11911 women) in his study may be behind this finding. Kollmann found a significant difference between numbers of LBW babies in major and minor placenta previa which did not be seen in present study. ${ }^{8}$ The birth weight of PP woman babies $( \pm 2560 \mathrm{gm})$ was less than that reported by NPP women $( \pm 3674 \mathrm{gm})$. Yeniel and Weiner reported the same findings. Unsurprisingly; because the number of preterm babies in PP women was higher than NPP women in all mentioned studies. ${ }^{5,7}$

There are some interesting points should be discussed in present study. Firstly; this is the first study which addressed the effect of PP on feto-maternal blood flow. Secondly; all previous studies were retrospective studies; however present study was prospective one. Thirdly; the ultrasound and Doppler examinations were performed by one investigator to decrease interobserver errors. Finally, authors were able to recruit present calculated sample size for achieving sufficient power to detect a clinically significant difference according to present primary outcome.

However, the present work had some limitations. First, the small sample size that was available for the final analysis at the end of the study (103 in PP women and 100 in NPP women). Secondly; in present study authors assessed only uterine and umbilical arteries blood flow; however, authors did not deal with other fetal blood vessels. Thirdly; the heterogenicity of included PP women might affected present results. Fourthly; authors did not care about placenta accreta or maternal outcome because it would take us away from present primary outcome, but it should be addressed in another study.

\section{CONCLUSION}

Placenta previa is not associated with low birth weight. Neither uterine nor umbilical artery is affected in patients with placenta previa. The relation between low birth weight and placenta previa can be explained by increased rate of preterm delivery.

\section{Funding: No funding sources \\ Conflict of interest: None declared}

Ethical approval: The study was approved by the Institutional Ethics Committee

\section{REFERENCES}

1. Mohamed MA, Mohammed AH. Parallel vertical compression sutures to control bleeding in cases of placenta previa and accreta. J Matern Fetal Neonatal Med. 2017;16:1-5.

2. Umazume $\mathrm{T}$, Hayasaka $\mathrm{S}$, Kato $\mathrm{F}$, Ishikawa $\mathrm{S}$, Morikawa M, Minakami H. Sudden maternal hypoxemia during elective cesarean section in a woman with placenta previa. Clin Case Rep. 2017;5(10):1668-71.

3. Harper LM, Odibo AO, Macones GA, Crane JP, Cahill AG. Effect of placenta previa on fetal growth. Am J Obstet Gynecol. 2010;203(4):330.e1-5.

4. Soyama H, Miyamoto M, Ishibashi H, Takano M, Sasa H, Furuya K. Relation between Birth Weight and Intraoperative Hemorrhage during Cesarean Section in Pregnancy with Placenta Previa. PLoS One. 2016;11(11):e0167332.

5. Weiner E, Miremberg H, Grinstein E, Mizrachi Y, Schreiber L, Bar J, et al. The effect of placenta previa on fetal growth and pregnancy outcome, in correlation with placental pathology. J Perinatol. 2016;36(12):1073-8. 
6. Rosenberg T, Pariente G, Sergienko R, Wiznitzer A, Sheiner E. Critical analysis of risk factors and outcome of placenta previa. Arch Gynecol Obstet. 2011;28:47-51.

7. Yeniel AO, Ergenoglu AM, Itil IM, Askar N, Meseri R. Effect of placenta previa on fetal growth restriction and stillbirth. Arch Gynecol Obstet. 2012;286(2):295-8.

8. Kollmann M, Gaulhofer J, Lang U, Klaritsch P. Placenta praevia: incidence, risk factors and outcome. J Matern Fetal Neonatal Med. 2016;29(9):1395-8.

9. Weiner E, Miremberg H, Grinstein E, Schreiber L, Ginath S, Bar J, et al. Placental histopathology lesions and pregnancy outcome in pregnancies complicated with symptomatic vs. non-symptomatic placenta previa. Early Hum Dev. 2016;101:85-9.

10. Ananth CV, Demissie K, Smulian JC, Vintzileos AM. Relationship among placenta previa, fetal growth restriction, and preterm delivery: a population-based study. Obstet Gynecol. 2001;98(2):299-306.

11. Shady NW, Sallam HF, Abbas AM. Placenta accreta and emergency cesarean delivery correlates to cervical length and transcervical placental thickness measurement. Int J Reprod Contracept Obstet Gynecol. 2017;6:4808-13.

12. Poon LC, Volpe N, Muto B, Yu CK, Syngelaki A, Nicolaides KH. Second-trimester uterine artery Doppler in the prediction of stillbirths. Fetal Diagn Ther. 2013;33:28-35.

13. Cho HY, Hwang HS, Jung I, Park YW, Kwon JY, Kim YH. Diagnosis of placenta accreta by uterine artery Doppler velocimetry in patients with placenta previa. J Ultrasound Med. 2015;34(9):1571-5.

14. Ali MK, Amin ME, Amin AF, Abd El Aal DEM. Evaluation of the effectiveness of lowdose aspirin and omega 3 in treatment of asymmetrically intrauterine growth restriction: A randomized clinical trial. Eur J Obstet Gynecol Reprod Biol. 2017;210:231-5.

15. Royal College of Obstetricians and Gynaecologists. The Investigation and Management of the Small-forGestational-Age. Green-top Guideline No. 31. London: RCOG; 2014.

16. Royal College of Obstetricians and Gynaecologists. Placenta Praevia, Placenta Praevia Accreta and Vasa Praevia: Diagnosis and Management. Green-top Guideline No.27. London: RCOG; 2011.

17. Ali MK, Abbas AM, Yosef AH, Bahloul M. The effect of low-dose aspirin on fetal weight of idiopathic asymmetrically intrauterine growth restricted fetuses with abnormal umbilical artery Doppler indices: a randomized clinical trial. J Matern Fetal Neonatal Med. 2017;11:1-6.

18. Ferdos J, Rahman MM. Maternal experience of intimate partner violence and low birth weight of children: a hospital-based study in Bangladesh. PLoS One. 2017;12(10):e0187138.
19. Black RE, Allen LH, BhuttaZA. Maternal and child under nutrition: global and regional exposures and health consequences. Lancet. 2008;371:243-60.

20. Shariat M, Gharaee J, Dalili H, Mohammadzadeh Y, Ansari S, Farahani Z. Association between small for gestational age and low birth weight with attention deficit and impaired executive functions in 3-6 years old children. J Mat Fetal Neonatal Med. 2017;1:1-4.

21. Björkqvist J, Hovi P, Pesonen AK, Räikkönen K, Heinonen K, Järvenpää AL, et al. Adults who were born preterm with a very low birth weight reported a similar health-related quality of life to their termborn peers. Acta Paediatr. 2018;107(2):354-7.

22. Takahashi H, Ohkuchi A, Usui R, Suzuki H, Baba Y, Matsubara S. Matsubara-Takahashi cervix-holding technique for massive postpartum hemorrhage in patients with placenta previa with or without placenta accreta spectrum disorders. Int $\mathbf{J}$ Gynaecol Obstet. 2018;140:357-64.

23. Shazly SA, Badee AY, Ali MK. The use of multiple 8 compression suturing Asa novel procedure to preserve fertility in patients with placenta accreta: case series. Aus NZJ Obstet Gynaecol. 2012;52(4):395-9.

24. Betrán AP, Ye J, Moller AB, Zhang J, Gülmezoglu AM, Torloni MR. The increasing trend in caesarean section rates: global, regional and national estimates: 1990-2014. PloS One. 2016;11(2):e0148343.

25. To WW, Leung WC. Placenta previa and previous cesarean section. Int $\mathbf{J}$ Gynaecol Obstet. 1995;51(1):25-31.

26. Hendricks MS, Chow YH, Bhagavath B, Singh K. Previous cesarean section and abortion as risk factors for developing placenta previa. J Obstet Gynaecol Res. 1999;25(2):137-42.

27. Getahun D, Oyelese Y, Salihu HM, Ananth CV. Previous cesarean delivery and risks of placenta previa and placental abruption. Obstet Gynecol. 2006;107(4):771-8.

28. Yang Q, Wen SW, Phillips K, Oppenheimer L, Black D, Walker MC. Comparison of maternal risk factors between placental abruption and placenta previa. Am J Perinatol. 2009;26(4):279-86.

29. Sekiguchi A, Nakai A, Kawabata I, Hayashi M, Takeshita T. Type and location of placenta previa affect preterm delivery risk related to antepartum hemorrhage. Int J Med Sci. 2013;10(12):1683-8.

30. Qiu Z, Hu J, Wu J, Chen L. Prophylactic temporary abdominal aorta balloon occlusion in women with placenta previa accretism during late gestation. Med (Baltimore). 2017;96(46):e8681.

31. Hebbar SS, Rai L, Zainab R, Guruvare S, Adiga P, Mundkur A. Influence of placental position on obstetric morbidity in placenta previa. Int $\mathbf{J}$ Reprod Contracept Obstet Gynecol. 2014;3:585-91.

32. Kumari SJ, Bhavani V, Himabindu S, Madhumitha M. Placental migration in mid trimester low-lying placenta. IOSR-JDMS. 2016;15(1):150-6.

33. Hong DH, Kim E, Kyeong KS, Hong SH, Jeong EH. Safety of cesarean delivery through placental 
incision in patients with anterior placenta previa. Obstet Gynecol Sci. 2016;59(2):103-9.

34. Ishibashi H, Miyamoto M, Shinnmoto H, Murakami W, Soyama H, Nakatsuka $M$, et al. Cervical varicosities may predict placenta accreta in posterior placenta previa: a magnetic resonance imaging study. Arch Gynecol Obstet. 2017;296(4):731-6.

35. Vahanian SA, Lavery JA, Ananth CV, Vintzileos A. Placental implantation abnormalities and risk of preterm delivery: a systematic review and metaanalysis. Am J Obstet Gynecol. 2015;213(4 Suppl):S78-90.
36. Bernstein IM, Horbar JD, Badger GJ, Ohlsson A, Golan A. Morbidity and mortality among very-lowbirth-weight neonates with intrauterine growth restriction. Am J Obstet Gynecol. 2000;182:198-206.

Cite this article as: Ali MK, Mahfouz IS, Abbas AM, Sayed EH. The effect of placenta previa on fetal weight and feto-maternal blood flow: a prospective cohort study. Int J Reprod Contracept Obstet Gynecol 2018;7:4485-92. 